\title{
Ethylene decomposition with a wire-plate dielectric barrier discharge reactor: parameters and kinetic study
}

\author{
T. J. $\mathrm{Ma}^{2} \cdot$ W. S. $\operatorname{Lan}^{1}$
}

Received: 9 October 2013/Revised: 5 November 2013/Accepted: 14 March 2015/Published online: 9 April 2015

(C) Islamic Azad University (IAU) 2015

\begin{abstract}
Ethylene is an undesirable compound for the storage of horticultural products. The traditional freshkeeping method of fruits and vegetables is refrigeration. However, even in refrigeration environment, ethylene is released by horticultural products themselves or other sources. The residual ethylene can accelerate maturation and corruption of horticultural products and thus should better be wiped away. The technique of dielectric barrier discharge was applied to decompose ethylene. Under electric discharge, many energetic and highly reactive species can be produced, which can react with and decompose the chemical compounds in contact with them. In this study, the efficiency of ethylene removal using dielectric barrier discharge reactor was studied. Ethylene removal rates were affected by many factors, such as gas discharge gap, wire distance, flow rate, ethylene initial concentration and humidity. The kinetics of ethylene removal was studied. To disintegrate ethylene, the optimal discharge gap was $3 \mathrm{~mm}$, wire distance $0.5 \mathrm{~mm}$, gas flow rate $3.5 \mathrm{~L} \mathrm{~min}^{-1}$ and humidity $61 \%$. Two kinetics models were selected for ethylene decomposition, and experimental results could fit the model with a maximum absolute error of $4 \%$. With optimal discharge condition, ethylene can totally be removed. In the future,
\end{abstract}

W. S. Lan

lanwshao@163.com

1 Shenzhen R\&D Key Laboratory of Alien Pest Detection Technology, Animal \& Plant Inspection and Quarantine Technical Center, Shenzhen Entry-Exit Inspection and Quarantine Burea, 1011 Fuqiang Road, Shenzhen 518045, China

2 College of Food Science and Engineering, Beijing University of Agriculture, Beijing 102206, China decomposition of ethylene by dielectric barrier discharge technology will be a promising method to keep fruits and vegetables fresh.

Keywords Decomposition - Dielectric barrier discharge reactor $\cdot$ Ethylene $\cdot$ Kinetics

\section{Introduction}

Ethylene $\left(\mathrm{C}_{2} \mathrm{H}_{4}\right)$, as a plant hormone, is used in agriculture to force the ripening of fruits and vegetables, even at partper-billion (ppb; $\mathrm{nL} \mathrm{L}^{-1}$ ) to part-per-million (ppm; $\mathrm{mL} \mathrm{L}^{-1}$ ) concentrations (Nathan et al. 1984; Saltveit 1999). The accumulated ethylene concentration in the storage container could be beyond $200 \mathrm{ppm}$ (Eschbach et al. 2000). It is essential to decrease the content of ethylene in horticultural storage facilities to extend the fresh-keeping time of fruits and vegetables.

Conventional techniques for ethylene removal mainly include adsorption, $\mathrm{K}_{2} \mathrm{MnO}_{4}$ oxidation (Peng et al. 2002), catalytic oxidation (Liang et al. 2009), photo-catalysis (Sun 2007) and biological methods (Liu and Cho 2006). However, these methods have some unavoidable drawbacks. For instance, adsorbent may be invalid because of some aerosol particles, $\mathrm{K}_{2} \mathrm{MnO}_{4}$ oxidation and catalytic oxidation are complicated, and photo-catalysis and biological method have low removal rates. Therefore, an alternative approach is needed to keep fruits fresh.

For the past few years, nonthermal plasma (NTP) techniques, such as dielectric barrier discharge (DBD), corona discharge and glow discharge, have been applied to decompose volatile organic compounds (VOCs) (Jarrige and Vervisch 2007; Grabowski et al. 2007; Van Durme et al. 2009; Bai et al. 2010; Vandenbroucke et al. 2011; 
Indarto 2012; Raju et al. 2013). This technique has many advantages, including moderate operation conditions (normal temperature and atmospheric pressure), low cost, a compact system and short residence times (Oda 2003; Mizuno 2007; Fridman 2008; Vandenbroucke et al. 2012). There is little information available in the literature about degradation of ethylene in fruit and vegetable preservation. DBD technique is a potential alternative for degradation of ethylene. In present study, ethylene decomposition by DBD was systemically studied and the reaction kinetics was analyzed.

\section{Materials and methods}

\section{Apparatus}

The experimental setup is illustrated in Fig. 1.

Ethylene gas streams of different concentrations were generated by mixing pure $\mathrm{C}_{2} \mathrm{H}_{4}$ gas (>99.5\%) from cylinder and the ambient air. Two sets of mass flow controllers (MFC) were used to regulate the flow rates. Meanwhile, a device generating water vapor was set in the air pathway and water vapor of different concentrations was obtained by adjusting flow rates of the bypass. Plasma was generated in a DBD reactor at atmospheric pressure and ambient temperature. Effluent gas was analyzed by gas chromatography.

\section{Reactor and power supply}

A wire-plate DBD reactor was used in this study (Fig. 2). The structure of the reactor was a hollow cuboid $(210 \mathrm{~mm} \times 60 \mathrm{~mm} \times 16 \mathrm{~mm})$ made of epoxy resin boards with thickness $5 \mathrm{~mm}$. The top and bottom planes acted as dielectric barriers (dielectric constant, $\varepsilon=3.6$ ). Several paralleled stainless wires of diameter $0.5 \mathrm{~mm}$ were installed in the reactor profile and connected to form the inner electrode (high-voltage electrode). Two stainless plates $(100 \mathrm{~mm} \times 45 \mathrm{~mm})$ were fixed on the top and bottom surface to become ground electrodes. The discharge length was $10 \mathrm{~cm}$, and the discharge gap was varied: 3,5 and $7 \mathrm{~mm}$.

Electrical discharge was ignited by applying AC high voltage in the range from 0 to $40 \mathrm{kV}$ (peak-to-peak), supplied by an amplifier and a function generator (Vareg, Switzerland) in the frequency range from 8 to $30 \mathrm{kHz}$. Meanwhile, another parameter, duty ratio, could be regulated ranging from 1 to $100 \%$.

\section{Electrical measurements}

The average power dissipated in the discharge was measured by the Lissajous method (Zhao et al. 2009), by plotting the charges transferred through the gas $\left(\mathrm{Q}_{\mathrm{DBD}}\right)$ versus applied voltage on the $\mathrm{DBD}$ reactor $\left(\mathrm{U}_{\mathrm{DBD}}\right)$. Voltage, charge and current waveforms were monitored by a digital oscilloscope (Tektronix TDS 2002). Discharge
Fig. 1 Schematic diagram of experimental apparatus. 1 Air compressor, $2 \mathrm{H}_{2} \mathrm{O}$ vapor generator, 3 Hydrometer, 4 Oscillograph, 5 DBD reactor, 6 High-voltage power supply, 7 Digital power meter, 8 Gas chromatograph

Fig. 2 DBD reactor
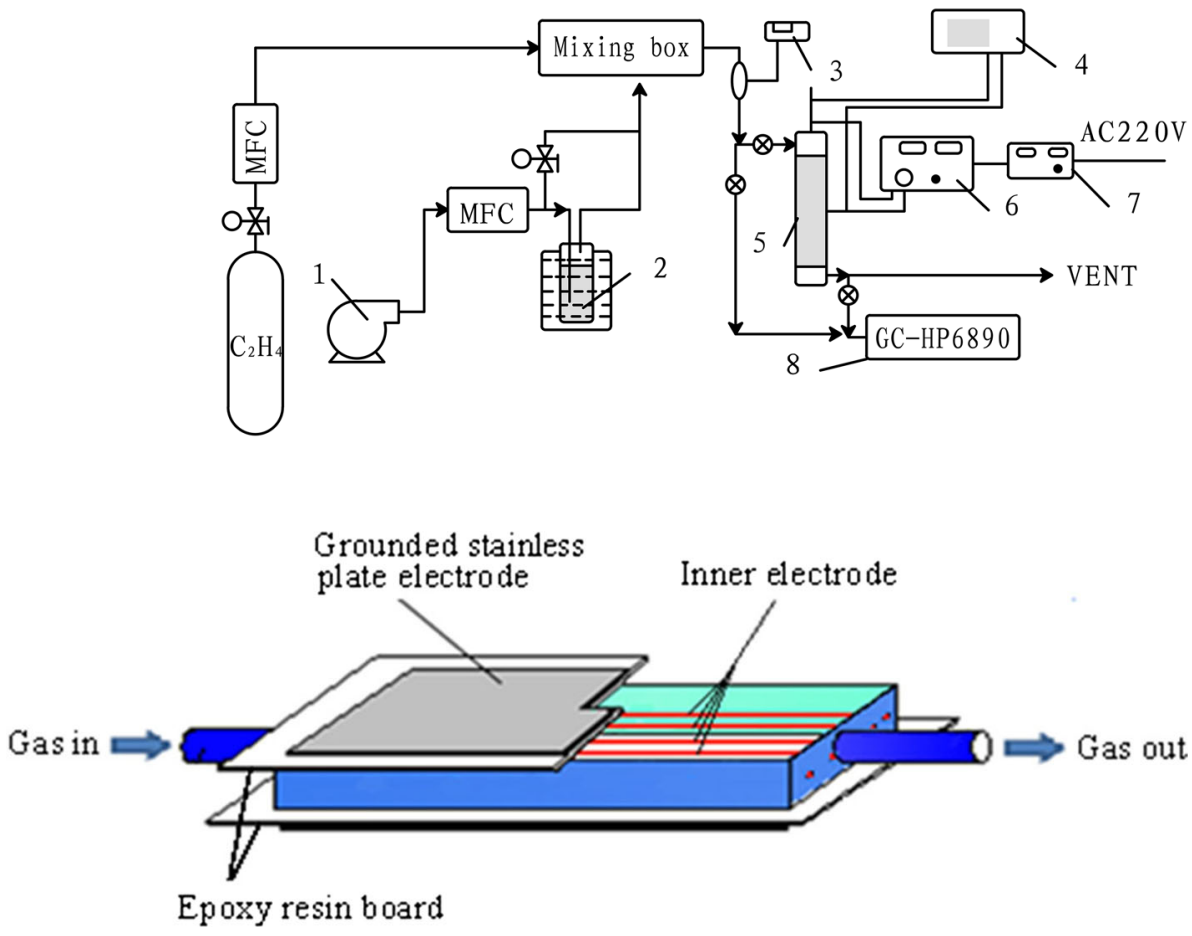
voltage was measured by a high-voltage probe (Tektronix P6015A 1000:1).

\section{Gas analysis}

Experiments were performed at atmospheric pressure and ambient temperature in air with small amounts of ethylene (10-240 ppm). Ethylene concentration was diagnosed by a gas chromatograph (HP6890) with flame ionization detector (FID) and a Kromat-ab-plotgap column (30 m length, $0.32 \mathrm{~mm}$ diameter).

Ethylene removal efficiency was calculated as follows:

$\eta_{\text {ethylene }}(\%)=\left(1-\frac{C_{\text {out }}}{C_{\text {in }}}\right) \times 100$

where $C_{\text {in }}$ and $C_{\text {out }}$ represent the inlet and outlet concentrations $\left(\mathrm{mg} \mathrm{m}^{-3}\right)$ of ethylene, respectively.

Specific energy density (SED) was defined as the average power dissipated in the discharge divided by the total gas flow rate, which could be calculated using the following relation:

$\operatorname{SED}(\mathrm{J} / 1)=\frac{P(\mathrm{~W})}{Q(1 / \min )} \times 60$

where $P$ and $Q$ represent discharge power $(W)$ and gas flow rate $\left(\mathrm{L} \mathrm{min}^{-1}\right)$, respectively.

\section{Results and discussion}

\section{Electrical characteristics of the discharge}

An electrical characterization of the plasma reactor must precede the chemical study (Mario et al. 2008; Huang and Ye 2009). This step is necessary in order to establish an energy balance of the process, as well as to determine and control energy consumption. The applied voltage and discharge current waveforms for the wire-plate DBD reactor tested are shown in Fig. 3a for a peak voltage of $12 \mathrm{kV}$, for the duty ratio of $40 \%$ and for the discharge gap of $3 \mathrm{~mm}$, which are plotted to obtain a Lissajous diagram as shown in Fig. $3 b$. They are typical for a filamentary DBD, alternating the voltage waveform both on the positive and on the negative.

Duty ratio is defined as the ratio of pulse duration to the period of rectangular wave form. The advantage of this supply is that it could generate higher current which could produce more active particles. When the voltage between two electrodes of the reactor is high enough to cause gas breakdown, the charge has phase transition, as a result of resistive losses in the discharge. In this case, the Lissajous diagram (charge plotted against voltage) becomes a parallelogram, as shown in Fig. 3b. When the voltage is not high enough to ignite plasma, the charge is in the same
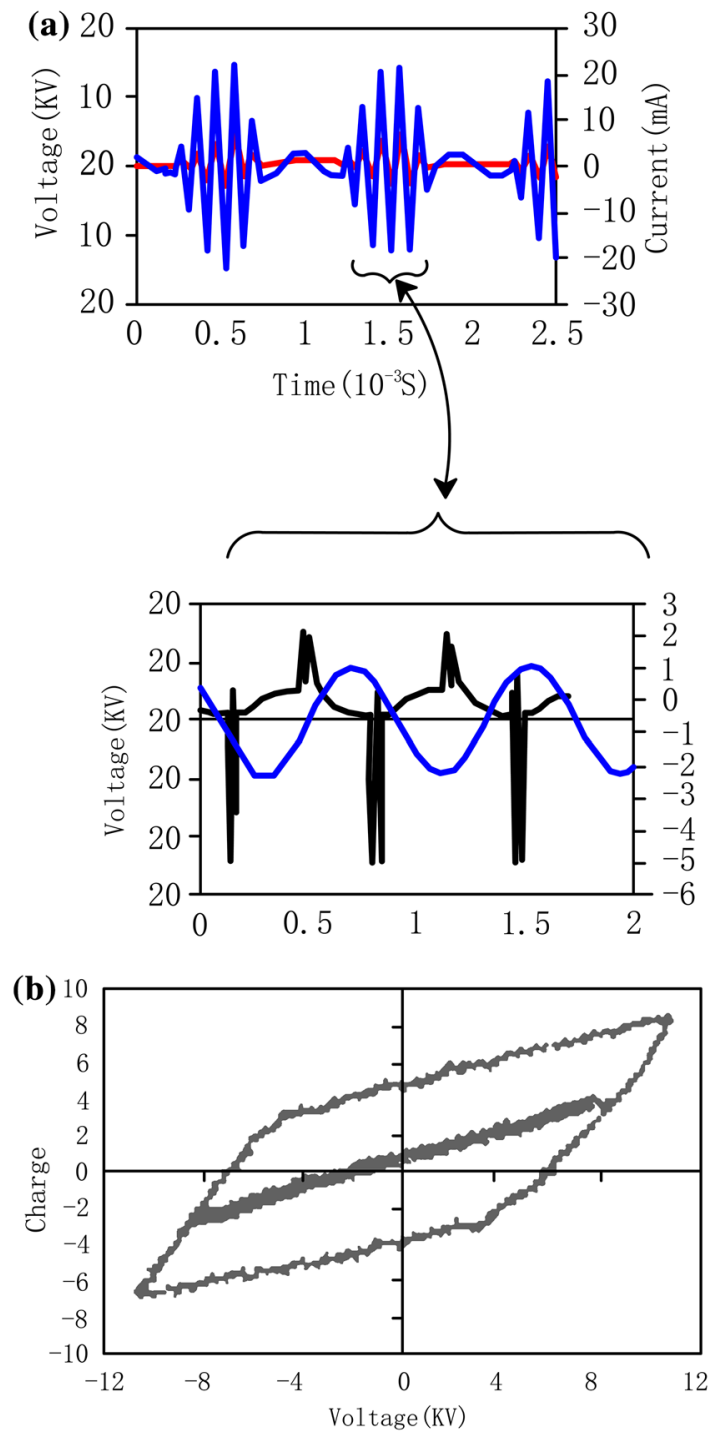

Fig. 3 Electrical characterization of the plasma reactor (duty ratio $40 \%$, amplitude of the applied voltage $12 \mathrm{kV}$ and discharge gap $3 \mathrm{~mm}$ ). a Voltage waveforms of DBD. b Typical voltage and current waveforms: V-Q Lissajous diagram of DBD

phase and the Lissajous diagram is a straight line that intercepts the origin, as shown in Fig. 3 b.

\section{Effects of gap on reactor performance}

The inter-electrode distance of the DBD reactor determines two main characteristics of the process: the reactor volume and the discharge behavior. The purpose of reducing the gap is to obtain a regular steady state. However, a decrease in the reactor gap reduces the residence time when the electron stays in the discharge zone. Thus, the inter-electrode distance must be optimized in order to improve the electricity consumption. Results of the ethylene removal for three different gaps: 3,5 and $7 \mathrm{~mm}$, are shown in 


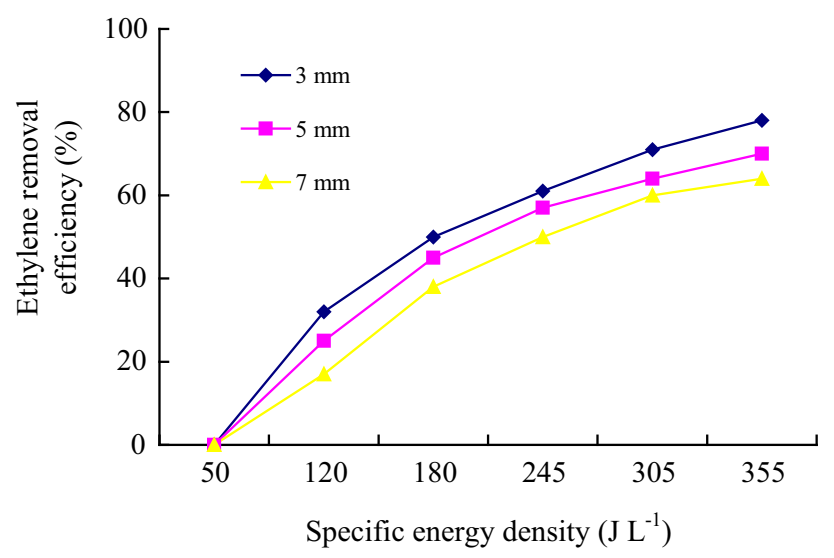

Fig. 4 Effects of gap on the reactor performance

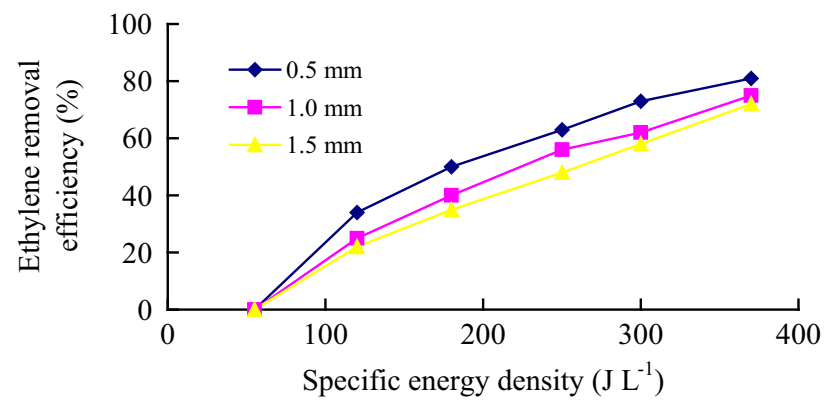

Fig. 5 Effects of wire distance on the reactor performance

Fig. 4. Comparison between three discharge gaps showed that the interval with $3 \mathrm{~mm}$ has lower energy consumption than other ones. A contrast of the $\mathrm{C}_{2} \mathrm{H}_{4}$ oxidation yield is shown in Fig. 4. $\mathrm{C}_{2} \mathrm{H}_{4}$ conversion yield of $80 \%$ was obtained at $360 \mathrm{~J} \mathrm{~L}^{-1}$ (gas flow rate $10 \mathrm{~L} \mathrm{~min}^{-1}$ ) for the reactor gap of $3 \mathrm{~mm}$, while an input power of about $360 \mathrm{~J} \mathrm{~L}^{-1}$ was just $60 \%$ for $7 \mathrm{~mm}$ gap.

\section{Effects of wire diameter on reactor performance}

Figure 5 shows the effect of wire diameter on reactor performance. It is clear that the smaller the wire diameter, the higher the ethylene removal efficiency. This can be explained by the fact that although the input power is in a definite range, the discharge strength will depend on the discharge area. The smaller the wire diameter, the higher the related discharge area.

\section{Effect of gas flow on reactor performance}

Dependence of ethylene removal efficiency on input energy with the gas flow rate ranging from 3.5 to $20.2 \mathrm{~L} \mathrm{~min}^{-1}$ in the DBD reactor is shown in Fig. 6. The initial concentration of ethylene was $80 \mathrm{ppm}$. Ethylene removal efficiency increased with the decrease in the gas flow rate. Almost all ethylene was removed at a gas flow

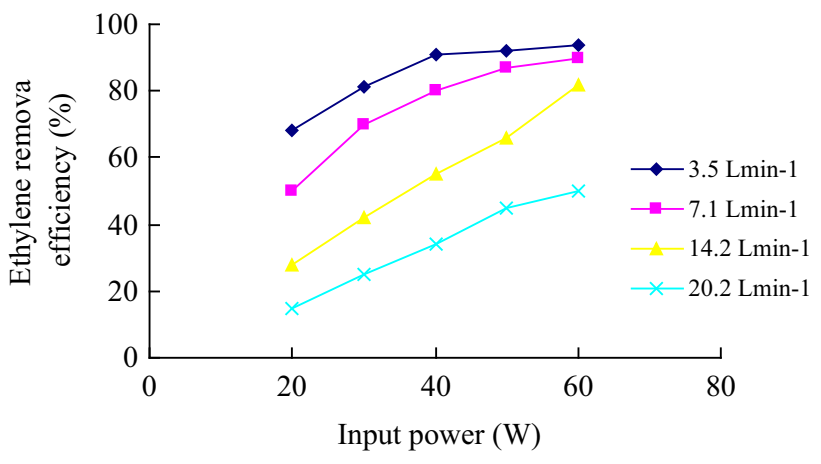

Fig. 6 Dependence of ethylene removal efficiency on input energy for selected gas flow rates in the DBD reactor

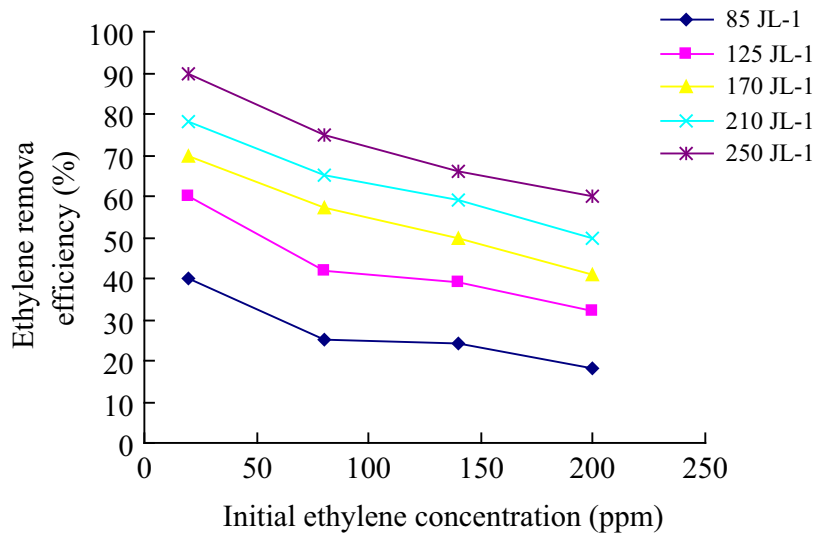

Fig. 7 Effects of initial concentration on the reactor performance

rate of $3.5 \mathrm{~L} \mathrm{~min}^{-1}$ and under the SED of $60 \mathrm{~W}$. Decreasing the gas flow rate, namely increasing the retention time in the reactor, would cause that a molecule of the gas was submitted to an increasing number of plasma discharges and the probability of collision between ethylene molecules and electrons improved, which resulted in a higher ethylene removal efficiency.

\section{Influence of initial concentration on reactor performance}

Figure 7 shows the ethylene removal efficiency as a function of its initial concentration between 16 and $200 \mathrm{ppm}$. These experiments were carried out under SED of $85,125,170,210$ and $250 \mathrm{~J} \mathrm{~L}^{-1}$, respectively. The conversion of ethylene decreased with the increase in initial ethylene concentration. In the DBD reactor, the removal efficiency for $16 \mathrm{ppm}$ of ethylene at a SED of $250 \mathrm{~J} \mathrm{~L}^{-1}$ was $90 \%$ and decreased to $60 \%$ for ethylene concentration of $200 \mathrm{ppm}$. A similar trend in the toluene conversion was observed at other values of SED. Increasing the initial concentration would cause the collision between ethylene molecules and electrons or other active particles. That is to say, when the SED is definite, there is a limitation for the removal of ethylene molecules. 


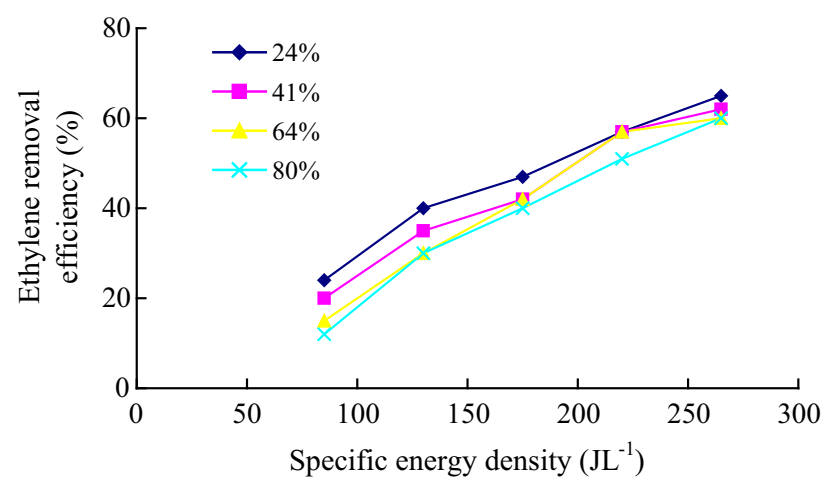

Fig. 8 Effects of humidity on the reactor performance (298 K)

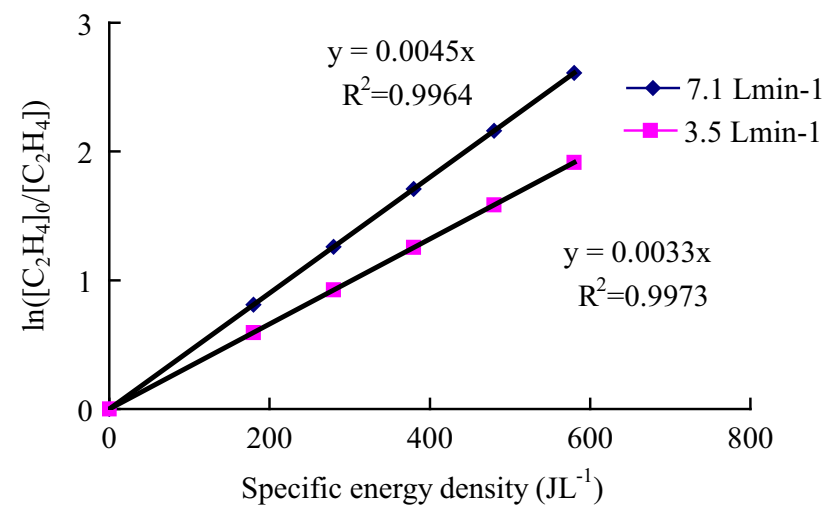

Fig. 9 Data fitting of function (3)

\section{Effects of humidity on ethylene removal efficiency}

Generally, humidity could affect the VOC conversion by NTP in two ways. Water molecules partially dissociate to form reactive species, such as $\cdot \mathrm{OH}$ radicals, which are important in VOC oxidation (Chung et al. 2000; Huang and Ye 2009).Water negatively influences VOC removal because of its electronegative characteristics. In the presence of high-concentration water, increased plasma attachment processes limit the electron density in the system and result in a reduced production of activated chemical species (Guo et al. 2006; Van Durme et al. 2007). In this study, humidity suppressed ethylene removal when relative humidity (RH) was beneath $64 \%(298 \mathrm{~K})$, but when it is above $64 \%$, the ethylene removal efficiency had no significant variation, as shown in Fig. 8. This phenomenon could be explained that when the $\mathrm{RH}$ was low, the electronegative characteristics were the critical factor, and when the RH was high, the two factors could interact. The fluctuation was not beyond $10 \%$ with the increase in RH, though humidity had an effect on ethylene removal efficiency.

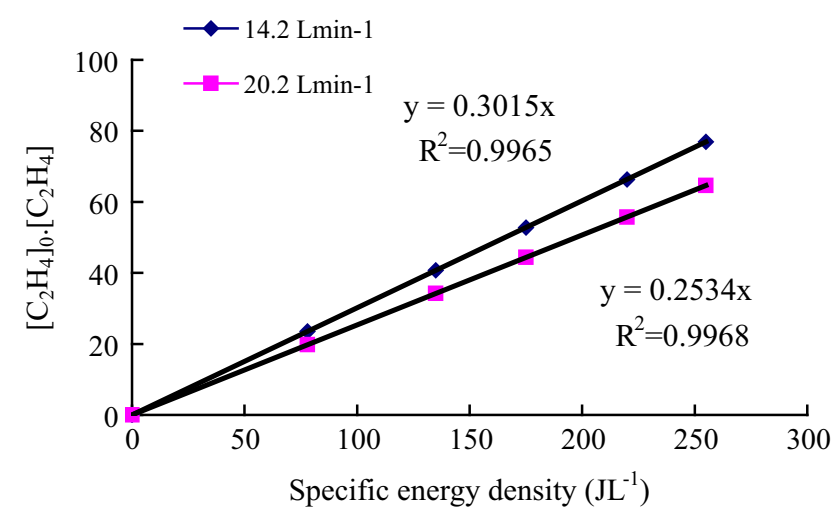

Fig. 10 Data fitting of function (4)

\section{Kinetics study}

The influence factors, discharge gap, wire diameter, gas flow, initial ethylene concentration and humidity, were studied. We discussed the kinetics in this section to optimize the plasma process.

According previous studies (Rosocha and Korzekwa 1999; Yan et al. 2001; Rudolph et al. 2002), for low or intermediate energy densities, the pollutant concentration $[X]$ could be expressed as a function of the input concentration $[X]_{0}$, energy density $E_{\mathrm{d}}$ and parameter $\beta$, which can depend on various parameters such as the input concentration $[X]_{0}$ or the reactor design:

$\operatorname{Ln} \frac{[X]_{0}}{[X]}=\frac{E_{\mathrm{d}}}{\beta}$

where $E_{\mathrm{d}}$ is the specific energy density, $[X]_{0}$ the concentration of the reactor inlet and $[X]$ the concentration of the reactor outlet.

When energy densities were high, another function was proposed:

$[X]_{0}-[X]=k_{1} E$

where $k_{1}$ is one of the rate constants of the four-step reaction.

According to the Fig. 6, obtained under the gas flow rate of 3.5, 7.1, 14.2 and $20.2 \mathrm{~L} \mathrm{~min}^{-1}$, the data were plotted by Figs. 9 and 10, and the data fitting is very well. The removal of ethylene is depended upon the amount of free radicals produced by the DBD reactor. The stronger the power, the higher the SED is. Under certain velocity of the ethylene, the ethylene removal is increased with the higher SED. Figure 9 is considered to be fitted to function (3). Figure 9 shows that when the gas flow rates were 3.5 and $7.1 \mathrm{~L} \mathrm{~min}^{-1}$, the $\beta$ values were 333 and 250 . However, when SED was lower (the gas flow rates were high), the figure was fitted for the function (4). Figure 10 shows that when the gas flow rate was $14.2 \mathrm{~L} \mathrm{~min}^{-1}, k_{1}$ was 0.301 and 
when the gas flow rate was $20.2 \mathrm{~L} \mathrm{~min}^{-1}, k_{1}$ was 0.253 . All the coefficients of correlation of the two were equal to or beyond $99.6 \%$.

\section{Conclusion}

Ethylene residual was effectively decomposed using DBD. Discharge gap, wire diameter, gas flow rate and initial concentration can affect ethylene decomposition significantly. The optimal discharge gap is $3 \mathrm{~mm}$ and wire distance is $0.5 \mathrm{~mm}$. Humidity is not critical for ethylene removal. Sixty-four percentage of humidity is a key factor, whether or not the electronegative characteristics play a significant role. Two kinetics models are selected for ethylene decomposition, and the experimental results fit the model with a maximum absolute error of about $4 \%$. Ethylene can be totally removed under optimal discharge conditions. With further intensive study, the technology of DBD will be developed for practical use in fruit and vegetable preservation in the near future.

Acknowledgments This research was financially supported by the program of Detection and Control of Spoilage Organisms and Pesticide Residues in Agricultural Products (PXM2012_014207_000011) and Innovative Platform Construction Team of Agricultural Products Safety and Pesticide Residue Analysis. This work was also supported by Shenzhen Science and Technology Project (Grant No. JC200903180677A) and Science and Technology Project of General Administration of Quality Supervision, Inspection and Quarantine (AQSIQ) (Grant No. 2013IK052), China.

\section{References}

Bai YH, Chen JR, Yang Y (2010) Degradation of organophosphorus pesticide induced by oxygen plasma: effects of operating parameters and reaction mechanisms. Chemosphere 81:408-414

Chung JW, Cho MH, Son BH (2000) Study on reduction of energy consumption in pulsed corona discharge process for $\mathrm{NO}(\mathrm{x})$ removal. Plasma Chem Plasma Process 20:495-509

Eschbach P, Griffin J, Reed N (2000) Ethylene concentrations in controlled atmosphere storage. In: 16th annual postharvest conference, Yakima, WA, pp 14-15

Fridman A (2008) Plasma chemistry. Cambridge University Press, Cambridge, pp 10-12

Grabowski LR, Van VEM, Pemen AJM (2007) Breakdown of methylene blue and methyl orange by pulsed corona discharge. Plasma Sources Sci Technol 16:226-232

Guo YF, Ye DQ, Chen KF, Tian YF (2006) Humidity effect on toluene decomposition in a wire-plate dielectric barrier discharge reactor. Plasma Chem Plasma Process 26:237-249

Huang HB, Ye DQ (2009) Combination of photocatalysis downstream the nonthermal plasma reactor for oxidation of gas-phase toluene. J Hazard Mater 171:535-541
Indarto A (2012) Decomposition of dichlorobenzene in a dielectric barrier discharge. Environ Technol 33:663-666

Jarrige J, Vervisch P (2007) Decomposition of gaseous sulfide compounds in air by pulsed corona discharge. Plasma Process $27: 241-255$

Liang WJ, Li J, Li J (2009) Abatement of toluene from gas streams via ferro-electric packed bed dielectric barrier discharge plasma. J Hazard Mater 170:633-638

Liu ZX, Cho MW (2006) Removal of ethylene over $\mathrm{KMnO}_{(4)} /$ $\mathrm{Al}_{(2)} \mathrm{O}_{(3)}-\mathrm{SiO}_{(2)}$. Bull Korean Chem Soc 27:2064-2066

Mario MS, Axel V, Esteban S, Jacques A (2008) Design of a DBD wire-cylinder reactor for $\mathrm{NO}_{\mathrm{x}}$ emission control: experimental and modelling approach. J Clean Prod 16:198-207

Mizuno A (2007) Industrial applications of atmospheric non-thermal plasma in environmental remediation. Plasma Phys Controll Fusion 49:1-15

Nathan R, Altman A, Monselise SP (1984) Changes in activity of polyamine biosynthetic-enzymes and in polyamine contents in developing fruit tissues of Murcott mandarin. Sci Hortic 22:359-364

Oda T (2003) Non-thermal plasma processing for environmental protection: decomposition of dilute VOCs in air. $\mathrm{J}$ Electrostat 57:293-311

Peng LT, Jiang YM, Jiang WB (2002) Ethylene control horticultural crops research progress. J Chin Food Sci 23:132-136

Raju BR, Reddy EL, Karuppiah J, Reddy PMK, Subrahmanyam C (2013) Catalytic non-thermal plasma reactor for the decomposition of a mixture of volatile organic compounds. J Chem Sci 125:673-678

Rosocha LA, Korzekwa RA (1999) Advanced oxidation and reduction processes in the gas phase using non-thermal plasmas. J Adv Oxid Technol 4:247-264

Rudolph R, Francke KP, Miessner H (2002) Concentration dependence of VOC decomposition by dielectric barrier discharges. Plasma Chem Plasma Process 22:401-412

Saltveit ME (1999) Effect of ethylene on quality of fresh fruits and vegetables. Postharvest Biol Technol 15:279-292

Sun QD (2007) Applications of photocatalized $\mathrm{TiO}_{2}$ to ethylene removal and freshness-holdable storage of vegetables and fruits. Vacuum 44:63-65

Van Durme J, Dewulf J, Sysmans W (2007) Abatement and degradation pathways of toluene in indoor air by positive corona discharge. Chemosphere 68:1821-1829

Van Durme J, Dewulf J, Demeestere K (2009) Post-plasma catalytic technology for the removal of toluene from indoor air: effect of humidity. Appl Catal B Environ 87:78-83

Vandenbroucke AM, Morent R, De Geyter N (2011) Decomposition of trichloroethylene with plasma-catalysis: a review. J Adv Oxid Technol 14:165-173

Vandenbroucke AM, Morent R, De Geyter N, Leys C (2012) Decomposition of toluene with plasma-catalysis: a review. J Adv Oxid Technol 15:232-241

Yan K, Van Heesch EJM, Pemen AJM (2001) From chemical kinetics to streamer corona reactor and voltage pulse generator. Plasma Chem Plasma Process 21:107-137

Zhao Q, Liu SZ, Tong HH (2009) Plasma technology and its application. National Defense Industry Press, Beijing, pp 40-41 